\title{
Impact of fuel-break structure on fire behaviour simulated with FIRETEC
}

\author{
F. Pimont ${ }^{1}$, J.-L. Dupuy ${ }^{1} \&$ R. R. Linn ${ }^{2}$ \\ ${ }^{I}$ I.N.R.A. Ecologie des Forêts Méditerranéennes (UR 629) Site Agroparc, \\ Domaine de Saint Paul, Avignon, France \\ ${ }^{2}$ Los Alamos National Laboratory MS: D401, Los Alamos, NM, USA
}

\begin{abstract}
This study focuses on the effects of fuel structure and in particular its spatial heterogeneity in the context of fuel-break design. The coupled atmospherewildfire behaviour model HIGRAD/FIRETEC is used to simulate wind fields and fire propagation in a complex landscape including forest-to-break and breakto-forest transitions. Two different Mediterranean ecosystems are used here: a Pinus halepensis (light canopy) and a Pinus pinaster (dense canopy). In both ecosystems, two forest zones are separated by a $200 \mathrm{~m}$ break.

The study is separated into two parts. First, the break-induced winds are simulated with FIRETEC. The impact of the break structure (cover fraction, clump size) on the mean wind and turbulence statistics are shown. A significant increase of wind velocity and turbulence amount is observed when the cover fraction is reduced within the break. In addition, at low cover fraction, the introduction of tree clumps also induces wind acceleration.

In the second part of the study, a fire line is ignited in the area upwind of the break and the fire propagation is computed using the precomputed wind fields of the first part of the study. The fire propagates in the upwind forest area before crossing the break and propagating in the downwind forest area. A decrease of fire intensity occurs after several meters of propagation on the fuel-break. This intensity decrease is significant when the cover fraction is lower or equal to $25 \%$, but negligible at $50 \%$. In addition, in the Pinus pinaster canopy, the fuel structure and especially clump size affect the fire damage.
\end{abstract}

Keywords: fire behaviour, fuel effects, fuel-break, physically-based model. 


\section{Introduction}

Forest fire prevention is mainly based on fuel reduction, in order to reduce fire intensity and crowning activities. However, the impact of fuel-break planning and forest protection policies on fire behaviour is not yet well known. They generally induce heterogeneous spatial patterns of vegetation, with some variations in fuel distribution and continuity. A better understanding of the fuel spatial pattern effects on fire intensity and crowning activities is frequently requested by forest managers for fuel-breaks planning. Several case studies can be found in the literature. Some of them are descriptions of real wildfires [1] and some others are modelling works [2-5]. Dupuy and Morvan [2], Linn et al. [3] and Pimont et al. [4] used physics-based models to assess fire propagation in different conditions of fuel treatments; however, they do not integrate both transitions from forest to clearing and clearing to forest, which affect both ambient conditions (wind) and fire. In [5], the authors study wildfire propagation at landscape scale in the context of multiple fuel-breaks, but the effects of each break on fire behaviour are postulated.

Wind simulation accuracy is generally known to be critical for detailed fire behaviour prediction [6]. In canopies, wind-flows are dominated by a turbulent regime, with short periods of strong gusts due to the Kelvin-Helmholtz instability [7]; they are locally strongly affected by clearings of several times the height of the canopy [8]. These effects should be included in models to reproduce fire behaviour in such complex landscapes.

HIGRAD/FIRETEC is a three dimensional physically-based model, which was started to be validated not only through comparisons with experimental data in grasslands [9], but also in crown fires in complex situations [10]. Simulations can be run at a scale of two meters near the ground and effects due to vegetation structure can be taken into account explicitly at this scale, in order to investigate the fuel structure impact on fire behaviour [3, 4]. In addition, FIRETEC's abilities to accurately simulate wind flows and turbulence over complex configurations such as fuel-breaks have already been demonstrated against detailed experimental data [11]. In the present study, we used FIRETEC to assess the impact of fuel-break structure on both wind flows and fire behaviour, in Maritime and Aleppo pine canopies. Fuel structure is described using the cover fraction and the tree clump dimension.

\section{Simulation characteristics}

The HIGRAD/FIRETEC modelling system is a three-dimensional two-phase transport model that solves the conservation equations of mass, momentum, energy and chemical species. A detailed description of the physical and chemical formulation of the model is available in [9-11]. FIRETEC includes representations of vegetation in order to simulate turbulent flows and fire propagation at fine scales $(\sim \mathrm{m})$ within and above the heterogeneous vegetation canopies. 


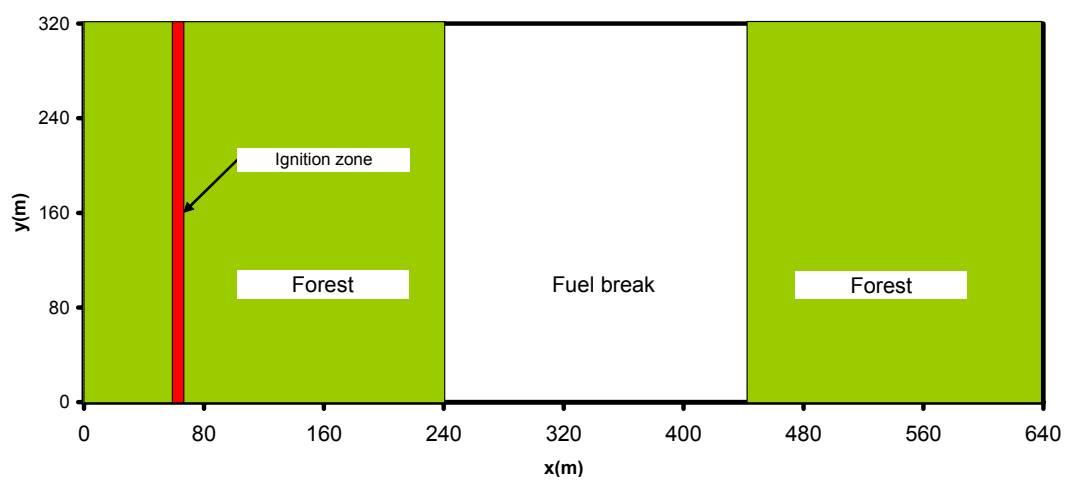

Figure 1: $\quad$ Top view of the fuel scene.

Table 1: $\quad$ Fuel physical characteristics.

\begin{tabular}{|l|c|c|c|c|c|}
\hline & $\begin{array}{c}\rho \\
\left(\mathrm{kg} . \mathrm{m}^{-3}\right)\end{array}$ & $\begin{array}{c}\sigma \\
\left(\mathrm{m}^{-1}\right)\end{array}$ & $\begin{array}{c}M \\
(\%)\end{array}$ & $\begin{array}{c}C B H \\
(\mathrm{~m})\end{array}$ & $\begin{array}{c}H \\
(\mathrm{~m})\end{array}$ \\
\hline Canopy: & & & & & \\
- Aleppo & 0.1 & 10000 & 100 & 4.75 & 12 \\
- Maritime & 0.5 & 5000 & 100 & 4.75 & 12 \\
\hline Understorey & 1.0 & 5000 & 70 & 0 & 0.5 \\
\hline
\end{tabular}

$\rho$ : bulk density; $\sigma$ : area to volume ratio; $M$ : moisture content; $C B H$ : crown base height; : height.

In the present study, the size of the computational domain was set to $640 \mathrm{~m} \times 320 \mathrm{~m} \times 615 \mathrm{~m}$ (fig. 1) with a horizontal resolution of $2 \mathrm{~m}$. The mesh was stretched in the vertical direction, starting from a $1.5 \mathrm{~m}$ resolution near the ground to $40 \mathrm{~m}$ at the top.

\subsection{Fuel characteristics}

The canopy height was set to $h=12 \mathrm{~m}$ in the stand, with an understorey of $50 \mathrm{~cm}$. The physical characteristics of the fuel are described in table 1 . The forest had a cover fraction of $C=75 \%$ and a tree clump size of $L=4 \mathrm{~m}$ (table 2). The fuelbreak area had the same understorey, but the canopy was modified. In this area, for the two pine species $(\mathrm{Pa}$ and $\mathrm{Pm}), \mathrm{C}$ ranged between 0 and $75 \%$ ( $\mathrm{HetO}$, Het 25, Het50, Het75) and $L$ ranged between 4 and $20 \mathrm{~m}(a, b, c)$. Homogenized vegetation at the fuel-break scale was also tested (Hom 25 was spatially homogeneous, but had the same load as Het25a, $b$ or $c$ ). It can be seen as an infinitely small clump size case.

\subsection{Wind simulation}

The initial wind flow was considered in equilibrium with the ground, which means that the initial velocity profile was logarithmic. The technique used to 
resolve conservation equations is similar to the large-eddy simulation technique (LES). For the analysis here, we mainly considered the mean streamwise velocity in the middle of the fuel-break, averaged on $3600 \mathrm{~s}$ of simulated time. Other statistics of the flow were also considered, but are not shown in the present paper.

Table 2: $\quad$ Spatial characteristics of canopy fuel on the fuel-break area.

\begin{tabular}{|c|c|c|c|c|c|c|}
\hline Case & $\begin{array}{c}\text { Pine } \\
\text { species }\end{array}$ & $\begin{array}{c}L \\
(\mathrm{~m})\end{array}$ & $\begin{array}{c}C \\
(\%)\end{array}$ & $\begin{array}{c}\rho_{\max } \\
\left(\mathrm{kg} \cdot \mathrm{m}^{-3}\right)\end{array}$ & $L A I$ & $\begin{array}{c}\text { Load } \\
\left(\mathrm{kg} \cdot \mathrm{m}^{-2}\right)\end{array}$ \\
\hline $\begin{array}{l}\text { PmHet } 75 a \\
\text { (no treatment) }\end{array}$ & \multirow[t]{7}{*}{$\begin{array}{l}\text { Maritime } \\
\text { pine }\end{array}$} & 4 & $75 \%$ & 0.5 & 7.2 & 2.7 \\
\hline PmHet50a & & 4 & $50 \%$ & 0.5 & 4.8 & 1.8 \\
\hline PmHet25a & & 4 & $25 \%$ & 0.5 & 2.4 & 0.9 \\
\hline PmHet $25 b$ & & 10 & $25 \%$ & 0.5 & 2.4 & 0.9 \\
\hline PmHet 25c & & 20 & $25 \%$ & 0.5 & 2.4 & 0.9 \\
\hline PmHom 25 & & 0 & $100 \%$ & 0.17 & 2.4 & 0.9 \\
\hline PmHet0 & & - & $0 \%$ & 0.0 & 0.0 & 0.0 \\
\hline $\begin{array}{l}\text { PaHet } 75 a \\
\text { (no treatment) }\end{array}$ & \multirow[t]{7}{*}{$\begin{array}{l}\text { Aleppo } \\
\text { pine }\end{array}$} & 4 & $75 \%$ & 0.1 & 2.9 & 0.54 \\
\hline PaHet50a & & 4 & $50 \%$ & 0.1 & 1.9 & 0.36 \\
\hline PaHet $25 a$ & & 4 & $25 \%$ & 0.1 & 0.97 & 0.018 \\
\hline PaHet $25 b$ & & 10 & $25 \%$ & 0.1 & 0.97 & 0.018 \\
\hline PaHet $25 c$ & & 20 & $25 \%$ & 0.1 & 0.97 & 0.018 \\
\hline PaHom 25 & & 0 & $100 \%$ & 0.033 & 0.97 & 0.018 \\
\hline PaHetO & & - & $0 \%$ & 0.0 & 0.0 & 0.0 \\
\hline
\end{tabular}

$d$ : clump size; $C$ : cover fraction; $\rho_{\max }$ : max bulk density; LAI: leaf area density.

\subsection{Fire simulation}

A fire line was ignited in the upwind forest area (fig. 1). The environmental wind fields used for boundary conditions were derived from the wind simulation previously described, in order to reproduce appropriate ambient conditions (mean wind profile and turbulence). Cyclic boundary conditions on the $y$ direction were used in order to simulate an infinite fire line incoming on the fuelbreak. Here, we studied the fire behaviour during its propagation, mainly based on fire intensity (computed from fuel consumption prediction). We also compared the impact of fuel treatments on fuel consumption on the fuel-break.

\section{Wind simulations}

The drag force within the canopy induced shearing in the wind velocity profile, which caused the development of Kelvin-Helmholtz instabilities, explicitly solved by the code. The mean vertical profile of streamwise velocity was characterized by an inflection near $z=2 / 3 h$, that can be seen on fig. $2 \mathrm{a} \& \mathrm{~b}$ (Simulation PaHet75a and PmHet75a). The inflexion was stronger in the maritime pine than in Aleppo pine, due to a higher leaf area density. 


\subsection{Effect of $\mathrm{C}$ on mean streamwise velocity}

In the presence of a fuel-break, the fuel reduction was associated with a decrease in the cover fraction ( $C$ from 0 to $50 \%$ ), which resulted in a lower average drag force on the break area. This drag reduction induced an increase of mean streamwise velocity in comparison to the forest values and a reduction of the strength of the inflexion, fig. 2 .

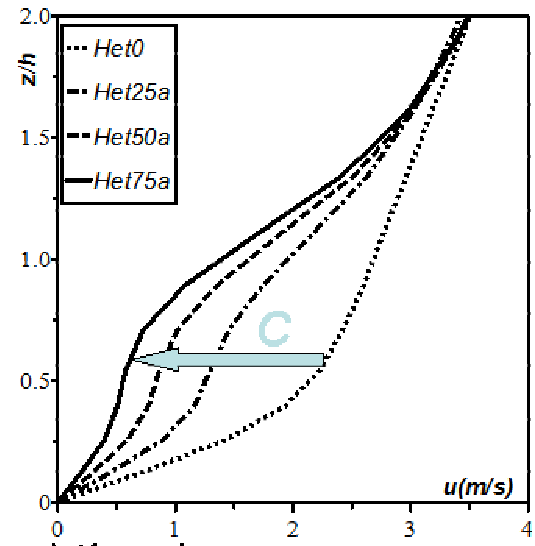

a) Aleppo pine

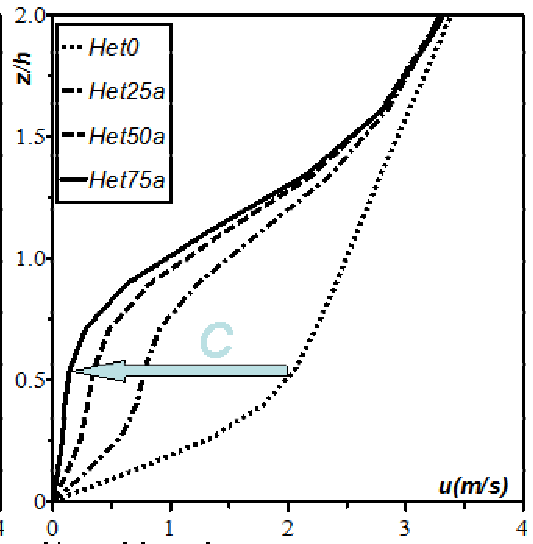

b) Maritime pine

Figure 2: $\quad$ Streamwise mean velocity profile in the middle of the fuel-break.

For a given cover fraction ( $C=25 \%$, for example), the increase of the clump size $L$ (from 4 to $20 \mathrm{~m}$ ) caused an increase of mean streamwise velocity (fig. $3 \mathrm{a}$ in maritime pine). Moreover, the homogenized case was characterized by the lowest values. The larger clump size was, the higher the mean streamwise velocity was. In addition, these clump size effects followed the same trend in Aleppo pine, but their magnitude was almost negligible, because the leaf area density was much smaller than in maritime pine. In addition, the clump size also affected the spatial variability of mean streamwise velocity. Fig. $3 b$ represents the variability of mean streamwise velocity along the $y$ axis, normalized by its mean value along the $y$ axis. It increased with the clump size.

\section{Fire simulation}

\subsection{Fire propagation within the break (case study PaHet25a)}

The case PaHet $25 a$ was the Aleppo pine forest with a fuel-break of $25 \%$ cover fraction and $4 \mathrm{~m}$ clump size. After the ignition, the fire propagated from the upwind forest area (fig. 4b), through the fuel-break (fig. 4c) and in the downwind forest area (fig. 4d). Fig. 4a represents the fire intensity as a function of position $x$ of the firefront in the domain. The greyed area represents the fuel-break 
position. At the beginning of the simulation, the intensity increased until the fire propagation was established. After the transition on the fuel-break, the intensity decreased. The minimum value was obtained when the fire had gone over $60 \mathrm{~m}$ within the fuel-break. Downwind to the leading edge, the fire intensity increased up to the same values as in the upwind forest area.

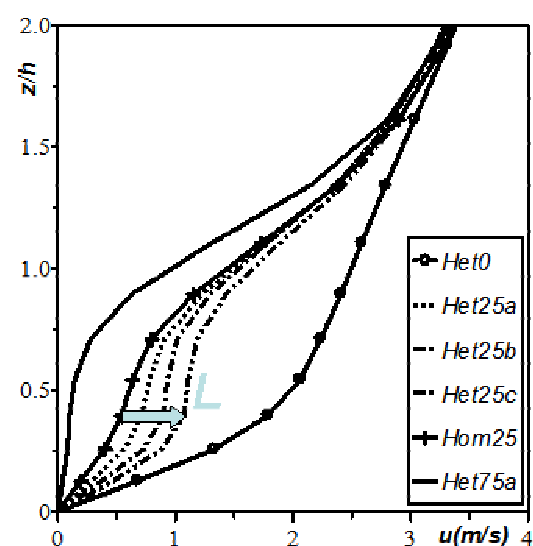

a) Streamwise velocity profile

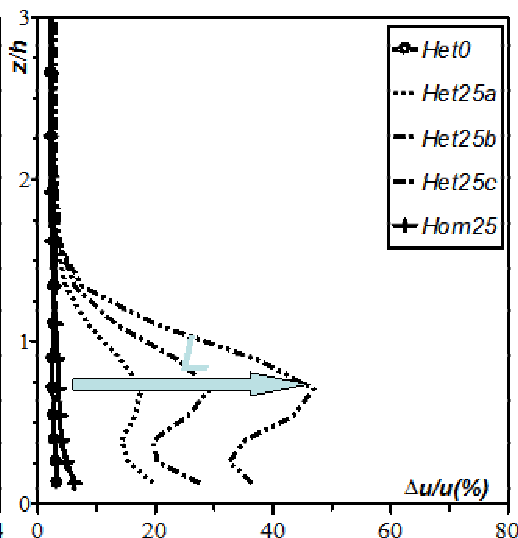

b) Streamwise velocity spatial variability

Figure 3: $\quad$ Effects of clump size $L$, on mean profiles and spatial variability of mean flow, in the middle of the maritime pine fuel-break.

The rate of spread was close to $0.8 \mathrm{~ms}^{-1}$, with no significant modification on the fuel-break.

\subsection{Effects of structure parameters}

Here, we compare the intensity diagrams for the different canopy structure. Fig. 5 represents the intensity for the different cover fractions (from 0 to $75 \%$ ) for Aleppo (a) and maritime (b) pine. As expected the intensity on the fuel-break decreased with cover fraction. However, it is worth noting that a fuel reduction at $50 \%$ (instead of $75 \%$ ) did almost not reduce fire intensity, whereas a reduction at $25 \%$ or even $0 \%$ was much more efficient. In addition, the intensity magnitude was much stronger in maritime pine than in Aleppo pine. This result is mainly due to the fact that the propagation in Aleppo pine was characterized by torching at this moderate wind speed, whereas the propagation in maritime pine was characterized by crowning (at high cover fraction). This difference was explained by the differences in bulk density between both pine species [4].

The effects of clump size on fire intensity were almost negligible in both ecosystems at $25 \%$ cover fraction (fig. 6). However, the homogenization of fuel at fuel-break scale (Hom 25) had significant effects on fire behaviour: for Aleppo pine, fire intensity and flame heights were lower in the homogenized case than in the heterogeneous cases (fig. 6a and 7a\&c); for maritime pine, fire intensity and 


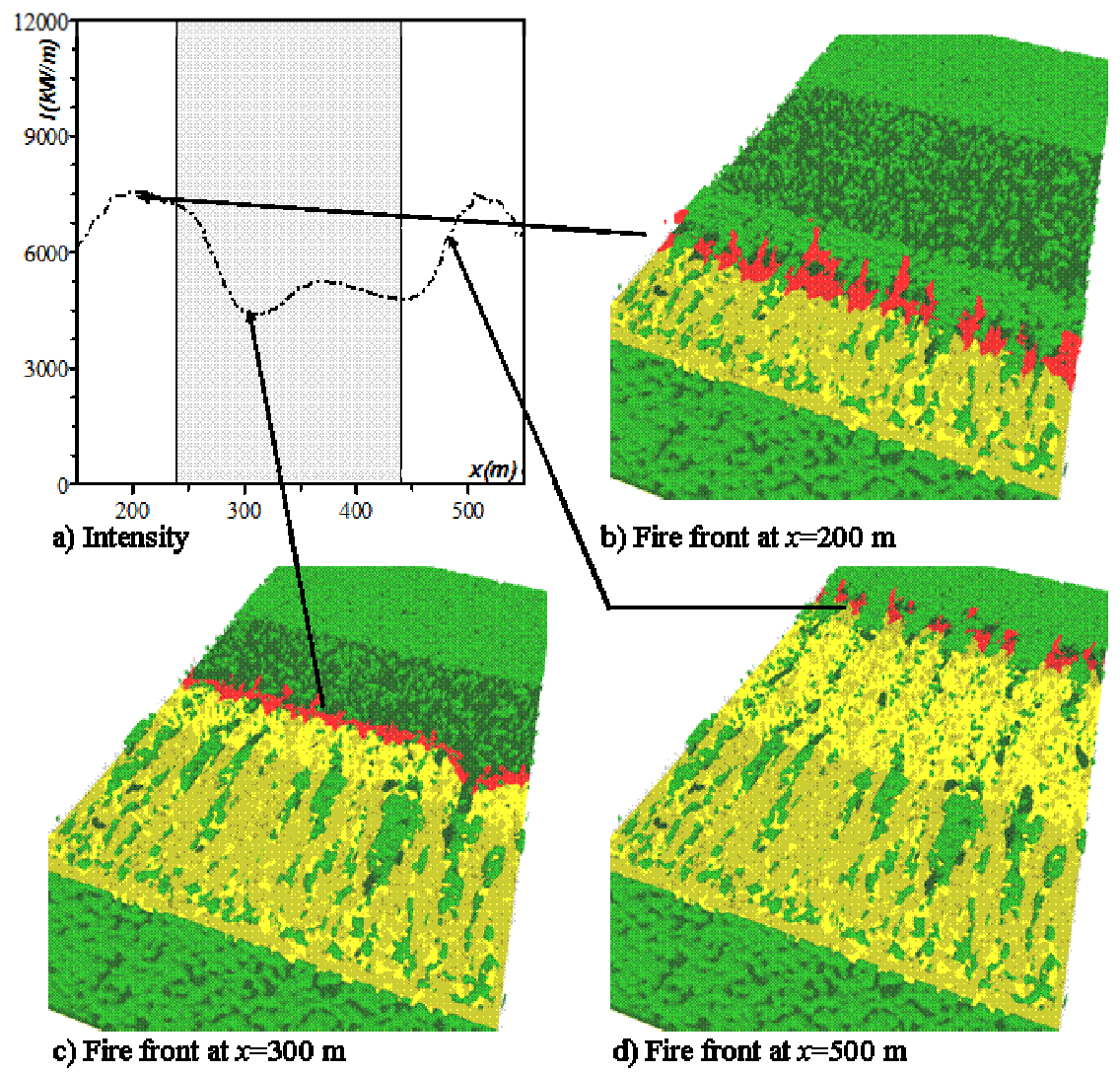

Figure 4: $\quad$ Fire behaviour on an Aleppo pine fuel-break $(\mathrm{C}=25 \%, d=4 \mathrm{~m})$.

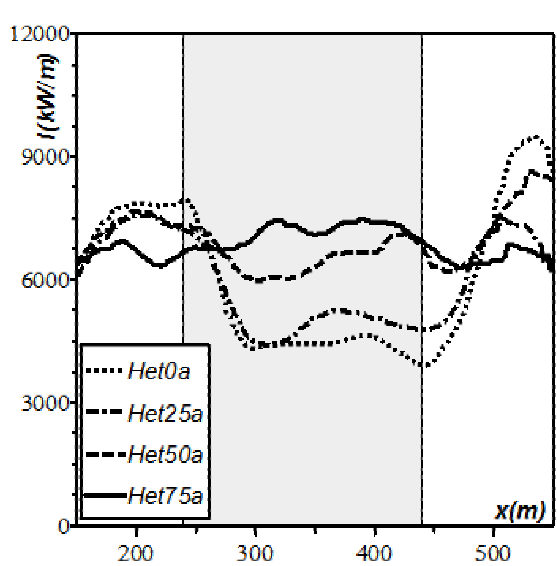

a) Aleppo pine

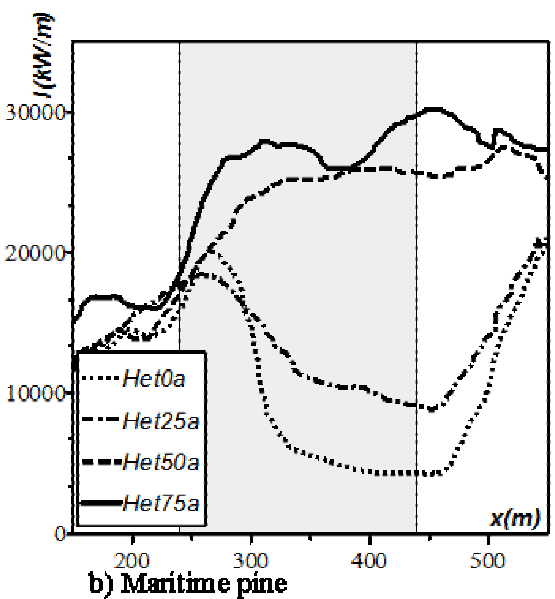

Figure 5: $\quad$ Intensities for different cover fractions in both pine stands.

WIT Transactions on Modelling and Simulation, Vol 48, (C) 2009 WIT Press www.witpress.com, ISSN 1743-355X (on-line) 


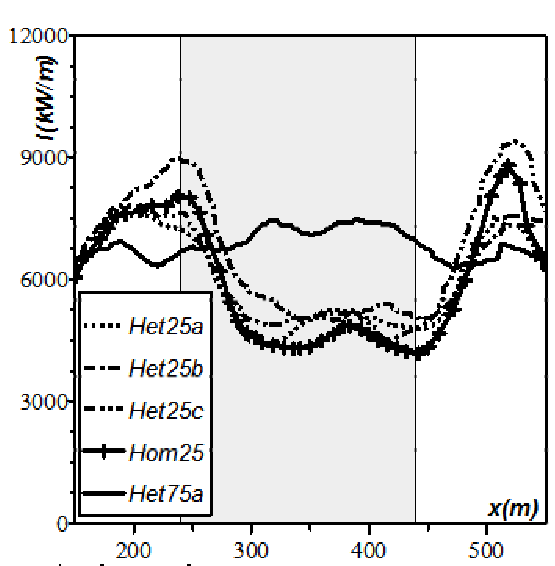

a) Aleppo pine

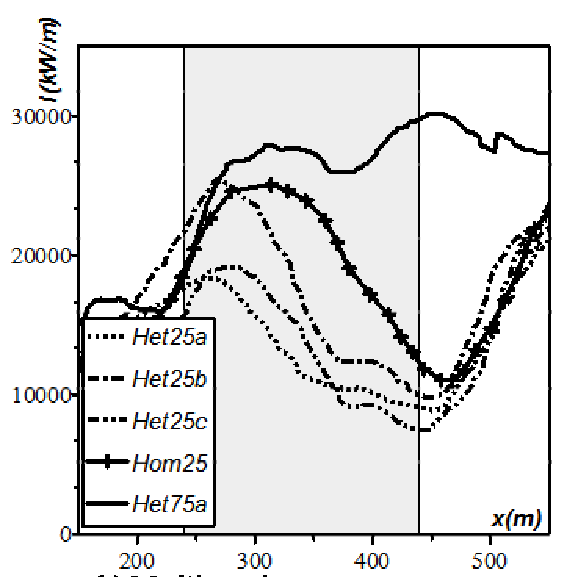

b) Maritime pine

Figure 6: Intensities for different clump sizes in both pine stands.

flame heights were higher in the homogenized case than in the heterogeneous cases (fig. $6 \mathrm{~b}$ and $7 \mathrm{~b} \& \mathrm{~d}$ ). The effects of fuel homogenization in both ecosystems were opposite.

\section{Discussion and conclusion}

\subsection{Comparison to some reference data}

Observed crown fire intensities usually range between 8000 and $40000 \mathrm{kWm}^{-1}$, with some exceptional events up to $150000 \mathrm{kWm}^{-1}$ [12]. In our simulations, intensities ranged between $7000 \mathrm{kWm}^{-1}$ for passive crown fires in Aleppo pine and $25-30000 \mathrm{kWm}^{-1}$ for active crown fires in dense maritime pine. These values are reasonable considering the fact that the wind is moderate in our simulation (12-13 $\mathrm{kmh}^{-1}$ as mean velocity and $25-30 \mathrm{kmh}^{-1}$ during gusts).

In the present study, the rate of spread was slightly affected by canopy fuel structure and generally ranged between 0.8 and $1 \mathrm{~ms}^{-1}$. There are not much affected by the different fuel treatments. In fact, the fuel treatments only deal with the canopy structure and does not affect the understorey, so that our results are consistent with the idea that the ROS are controlled by understorey fuel. Compared to [13], the ROS obtained in our study seem slightly too fast. They are also a little bit faster than the ones we used to get using FIRETEC [4]. The main difference is between these runs and previous ones is the use of an infinite fireline (cyclic boundary condition). This simulation is a 3D simulation (we can notice the crown streets generated by the code on fig. 4); however, the fact that the line is infinite prevents the fire from lateral indrafts that refresh the fire. This argument is supported by the fact that in the experiment used in [10] for their comparison, the fire spread in the middle of the plot is much faster than the fire spread close to the lateral sides, which is affected by these indrafts. Indeed, the rate of spread would probably have been much faster with a much larger 
firefront. Such an argument might explain the high values obtained in this particular study. In addition to this point, we used precomputed wind field for ambient wind condition assessment, that include resolved turbulence and gusts that are also likely to affect fire spread, instead of a constant ambient wind.
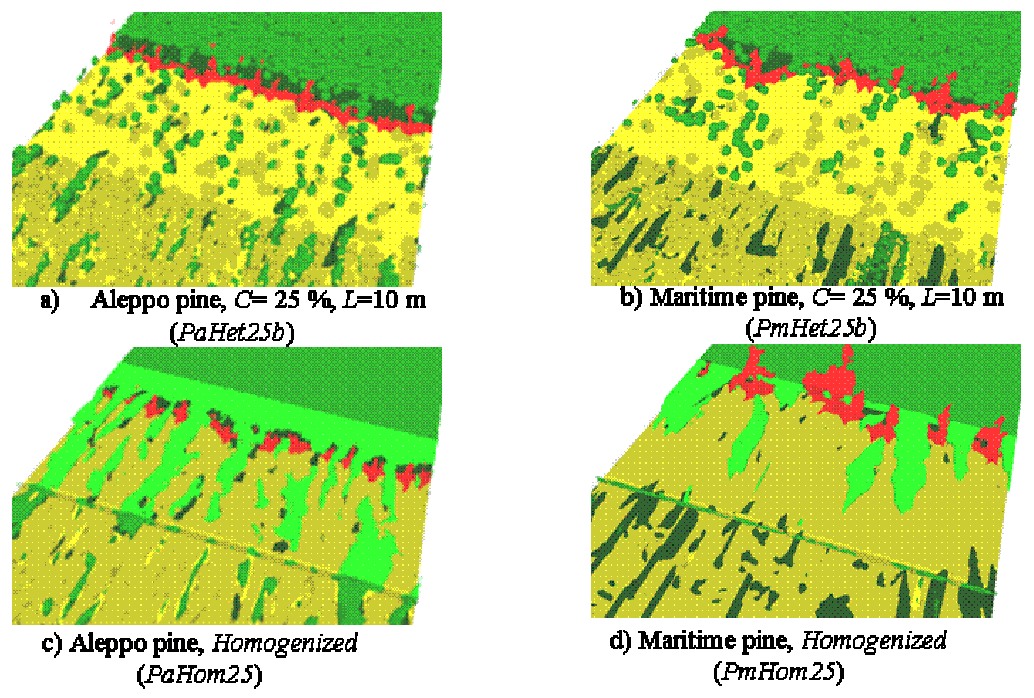

Figure 7: Fire behaviour on different fuel-breaks.

\subsection{Fuel structure effects}

The cover fraction had a strong effect on fire intensity, with a threshold effect between 25 and $50 \%$. It basically shows that a light thinning at $50 \%$ cover fraction might be inefficient. Results also suggest that the behaviour and heterogeneity effects are likely to be different in both ecosystems. With the moderate wind considered, the propagation in Aleppo pine is characterized by sparse torching, whereas the propagation is much more active in maritime pine. These results were already observed on smaller domain and with a finite fire line [4].

In addition to that, a detailed analysis of wind flow not presented here shows that the plumes in maritime pine are strong enough for an entrainment of downwind fresh air (negative streamwise velocity downwind of the fire) whereas the fire is just pushed by the wind (streamwise velocity always positive) in Aleppo pine. This behaviour can be understood in terms of "plume dominated" versus "wind driven" behaviour.

To summarize, this study of the break-induced winds and fires entailed a better understanding of the impact of the break structure. A significant increase of wind velocity and turbulence amount was observed with cover fraction reduction and the introduction of heterogeneous tree clumps induced wind acceleration. Fire intensity decreased after several meters of propagation within 
the fuel-break. The intensity reductions were significant when the cover fraction was lower or equal to $25 \%$. In addition, in Pinus pinaster canopy, fuel structure affected fire damage.

\section{References}

[1] Lambert, B., Casteignau, D., Costa, M., Etienne, M., Guiton, J-L., Rigolot, R., Analyse après incendie de six coupures de combustible. Réseau Coupures de Combustible. Editions de la Cardère, 85 p., 1999.

[2] Dupuy, J.L. \& Morvan, D., Numerical study of a crown fire spreading toward a fuel break using a multiphase physical model. International Journal of Wildland Fire, 14 (2), pp. 141-151, 2005.

[3] Linn, R.R., Winterkamp, J., Colman, J.J., Edminster, C., Bailey, J., Modeling interactions between fire and atmosphere in discrete element fuel beds. International Journal of Wildland Fire, 14, pp. 37-48, 2005.

[4] Pimont, F., Linn, R.R., Dupuy, J-L., Morvan, D., Effects of vegetation description parameters on forest fire behaviour with FIRETEC. Forest Ecology and Management, 234S, S120, 2006.

[5] Finney, M.A., Selia, R.C., McHugh, C.W., Ager, A.A., Bahro, B., Agee, J.K., Simulation of long-term landscape-level fuel treatment effects on large wildfires. International Journal of Wildland Fire, 16, pp. 712-727, 2007.

[6] Butler, B., Forthofer, J., Finney, M., McHugh, C., Stratton, R., Bradshaw, L., The impact of high resolution wind field simulations on the accuracy of fire growth predictions. Forest Ecology and Management, 234S, S85, 2006.

[7] Raupach, M.R., Bradley E.F., Ghadiri, H., A wind tunnel Investigation Into Aerodynamic Effect of Forest Clearing on the nesting of Abbott's Booby on Christmas Island. Internal report, CSIRO Centre for environmental Mechanics, Canberra, 1987.

[8] Raupach, M.R., Finnigan, J.J., Brunet, Y., Coherent eddies and turbulence in vegetation canopies: the mixing-layer analogy. Boundary-Layer Meteorology, 78, pp. 351-382, 1996.

[9] Linn, R.R., Cunningham, P., Numerical simulations of grass fires using a coupled atmosphere-fire model: basic fire behavior and dependence on wind speed. Journal of Geophysical Research, 110, D13107. 19 pp., 2005.

[10] Linn, R.R., Canfield, J., Winterkamp, J., Cunningham, P., Colman, J.J., Edminster, C., Goddrick, S.L., Numerical Simulations of Fires Similar to the International Crown Fire Modelling Experiment. Proceedings of the Sixth Symposium on Fire and Forest Meteorology, American Meteorological Society, Canmore, Alberta, 25-27 October 2005.

[11] Pimont, F., Dupuy, J-L., Linn, R.R., Dupont, S., Validation of FIRETEC wind-flows over a canopy and a fuel-break. Submitted to International Journal of Wildland Fire. Submitted. 19 p.

[12] Trabaud, L., Les feux de forêts. Editions France Sélection. 278 p, 1989.

[13] Taylor, S.W., Wotton, B.M., Alexander, M.E., Dalrymple, G.N., Variation in wind and crown fire behaviour in a northern jack pin-black spruce forest. Canadian Journal of Forest Research, 34, pp. 1561-1576, 2004. 